\title{
Atividade antimicrobiana in vitro de produtos antissépticos por meio de técnica time kill
}

\author{
Analysis of in vitro antimicrobial activity of antiseptics products by \\ means of time kill assay
}

RIALA6/1568

Hilda do Nascimento NÓBREGA* Joana Angélica Barbosa FERREIRA, Célia Maria Carvalho Pereira

Araújo ROMÃO, Ivano Raffaele Victorio de Filippis CAPASSO

“Endereço para correspondência: Laboratório de Produtos Não Estéreis, Instituto Nacional de Controle de Qualidade em Saúde (INCQS), Fundação Oswaldo Cruz (FIOCRUZ). Av. Brasil, 4365, Manguinhos, Rio de Janeiro, RJ. CEP 21040-900. E-mail: hilda.nobrega@incqs.fiocruz.br, hildanobrega@gmail.com

Recebido: 23.05.2013 - Aceito para publicação: 13.08.2013

\begin{abstract}
RESUMO
Inúmeros agentes químicos (álcoois, iodóforos, clorexidina, etc.) são utilizados em laboratórios e indústrias. Ao contrário dos desinfetantes, não há padrões e critérios específicos para avaliar a atividade de antissépticos. Neste trabalho foi estudada a atividade antimicrobiana de antissépticos, utilizando-se o ensaio Time Kill (Hobson \& Bolsen), que avalia a população de micro-organismos aeróbios em período de tempo específico, diante de agentes antimicrobianos. Foram avaliadas duas metodologias de recuperação dos microorganismos: filtração por membrana e semeadura em profundidade. A filtração por membrana foi menos sensível. A semeadura em profundidade demonstrou maior sensibilidade com maior contagem de colônias. De 25 amostras de produtos, os antissépticos à base de digluconato de clorexidina foram insatisfatórios e ineficazes para todas as cepas de micro-organismos de referência, correspondendo a $20 \%$ das amostras analisadas. Estes produtos apresentaram-se satisfatórios frente às cepas de origem clínica. Portanto, estes produtos devem ser utilizados com cautela e estudos adicionais são necessários, pois são escassas as informações sobre sua eficácia. Os dados deste estudo poderão auxiliar as ações de vigilância sanitária e de saúde pública na elaboração de futuras legislações, pois estes produtos são encontrados no comércio, mas sem seguir nenhuma legislação específica.
\end{abstract}

Palavras-chave. atividade antimicrobiana, antisséptico, tempo de morte, neutralização.

\begin{abstract}
Many chemicals (alcohol, iodophor, chlorhexidine, etc) are used in laboratories and industries. Unlike disinfectants, no specific norms and criteria have been standardized for evaluating the antiseptics activity. This study analyzed the antimicrobial activity of antiseptics using Time Kill Test (Hobson \& Bolsen). This assay assessed the evolution of a population of aerobic microorganisms in a specific period of time when tested against antimicrobial agents. Two different recovery methodologies were evaluated: membrane filtration and pour plate technique The membrane filtration assay was less sensitive. Pour plate technique showed high sensitivity with high colonies counts. Of 25 samples of products analyzed, only the chlorhexidine digluconate-based antiseptics were unsatisfactory, showing no efficacy on all reference micro-organisms strains, and corresponded to $20 \%$ of analyzed samples. However, they were efficacious against clinical strains. Therefore, these products should be used with caution and further studies are needed, as data on its efficacy have still been scarce. These findings might give support to the health surveillance and public health in establishing the future legislation, as these products have been available on the market, but without following any specific legislation.
\end{abstract}

Keywords. antimicrobial activities, antiseptic, time kill, neutralization. 


\section{INTRODUÇÃO}

Assepsia é o conjunto de medidas adotadas para impedir a introdução de agentes patogênicos no organismo e no ambiente e inclui procedimentos de antissepsia, desinfecção e esterilização ${ }^{1}$. A antissepsia consiste na utilização de produtos (microbiocidas ou microbiostáticos) sobre a pele ou mucosa com o objetivo de reduzir os micro-organismos existentes, e tais produtos são classificados como antissépticos. $\mathrm{Na}$ assistência à saúde, sua principal função é o preparo da pele, como higienização das mãos e antes de alguns procedimentos ${ }^{2}$.

Estudos realizados na Europa em pacientes de UTIs demonstraram que os micro-organismos mais encontrados foram as enterobactérias, seguidas pela P. aeruginosa. No Brasil, também é possível observar a ocorrência de Pseudomonas aeruginosa multirresistente em diferentes hospitais do Rio de Janeiro ${ }^{3-5}$.

O Ministério de Saúde define infecção hospitalar como aquela adquirida após a admissão do paciente e cuja manifestação ocorre durante a internação e em decorrência de procedimentos hospitalares ${ }^{2}$. Também a Lei 8.080, de 19 de setembro de $1990^{6}$, estabelece como objetivo e atribuição do Sistema Único de Saúde (SUS), "onde estão incluídas também ações de prevenção de infecções"

Muitos antissépticos se mostram mais eficazes em bactérias Gram-positivas do que em Gramnegativas, embora esta diferença não seja tão clara como na atividade dos antibióticos, de um modo geral, antissépticos e desinfetantes devem ser usados quando há estudos científicos que demonstrem benefício ou quando existe uma forte justificativa teórica para a utilização de germicidas $^{8,9}$.

Um número considerável de agentes químicos é utilizado tanto em laboratórios quanto nos estabelecimentos de saúde e nas indústrias, incluindo álcoois, iodóforos, fenóis sintéticos e compostos quaternários de amônio, clorexidina entre outros. Entretanto, não existe um antisséptico que atenda a todas as situações e necessidades encontradas, sendo preciso conhecer as características de cada um para que se tenham subsídios suficientes que permitam a escolha correta do produto, evitando custos excessivos e uso inadequado ${ }^{10}$.

Um antisséptico ideal deve ser capaz de destruir a forma vegetativa de todos os micro-organismos patogênicos, requerer tempo limitado de exposição e ser eficaz em temperatura ambiente, além de não ser corrosivo, apresentar baixa toxicidade para seres humanos e ser de baixo custo. O grau de seletividade para os agentes antissépticos pode variar, dependendo dos tecidos com os quais entram em contato ${ }^{11}$.

Os vários antissépticos e desinfetantes podem ser classificados de acordo com seu mecanismo de ação: agentes que desnaturam as proteínas; agentes que causam lise osmótica da célula; e agentes que interferem em processos metabólicos específicos levando à morte do micro-organismo ${ }^{10}$.

A clorexidina possui ampla atividade antimicrobiana, porém inativa os micro-organismos numa taxa muito mais lenta do que a do álcool etílico. Sua atividade persiste, embora sua eficácia seja reduzida por materiais orgânicos e altos valores de $\mathrm{pH}^{12}$.

Os álcoois (etílico, etanol, isopropanol) possuem excelente atividade contra todos os grupos de micro-organismos, exceto os esporos, e possuem baixa toxicidade, embora tenham tendência a ressecar a superfície da pele, devido à remoção dos lipídios. Além disso, não possuem atividade residual e são ativados por matéria orgânica. Por conseguinte, é necessário limpar a superfície da pele antes da aplicação do álcool ${ }^{13}$.

$\mathrm{O}$ iodo penetra rapidamente através da parede celular do micro-organismo. Seu efeito letal é atribuído à inativação de proteínas e ácidos nucleicos interferindo de modo letal nos processos de síntese de proteínas ${ }^{10}$.

Atualmente, a Resolução RDC $\mathrm{n}^{\circ} 42$ de 2010, torna pública a proposta de resolução "Diretrizes para Disponibilização de Preparação Alcoólica para Fricção Antisséptica das Mãos pelos Serviçõs de Saúde”. Essa portaria tem o objetivo de executar e promover a higienização das mãos nos serviços de saúde por meio de preparações alcoólicas, previstas na Aliança Mundial para a segurança do paciente, com o intuito de prevenir e controlar as infecções relacionadas à assístência à saúde, visando a segurança do paciente e dos profissionais de saúde ${ }^{14}$.

Soluções diluídas de iodo possuem atividade mais rápida do que a das concentradas. A razão para tal ainda não está totalmente esclarecida, mas foi sugerido que a diluição do PVP-I resulta no enfraquecimento da ligação do iodo com o polímero carreador, aumentando a concentração de iodo na solução. Assim, o iodóforo deve ser adequadamente diluído para alcançar a atividade antimicrobiana ${ }^{10}$.

Os compostos fenólicos exercem atividade antimicrobiana lesando as membranas plasmáticas, 
inativando as enzimas e desnaturando as proteínas. Os compostos de amônio quaternário são fortemente bactericidas contra as bactérias Gram-positivas e um pouco menos ativos contra as bactérias Gram-negativas ${ }^{15}$.

O controle da qualidade dos desinfetantes e antissépticos envolve análises químicas, toxicológicas e microbiológicas do rótulo. A análise microbiológica tem como objetivo comprovar a eficácia do produto para a finalidade a que se destina. Para avaliar a eficácia de desinfetantes, metodologias específicas foram estabelecidas (exemplos: Association of Official Analytical Chemists - AOAC, European Standards - EN), em que é recomendado o uso de micro-organismos de referência. No caso dos antissépticos, apesar da inexistência de metodologia oficial para produtos pronto-uso, também são utilizadas cepas de referência nos ensaios ${ }^{16}$.

Existem vários métodos para avaliação da atividade antimicrobiana de produtos antissépticos, dentre eles o protocolo do FDA, que inclui ensaios frente a: Staphylococcus aureus, Pseudomonas aeruginosa, Escherichia coli e Candida albicans. Na Europa, o Comitê Europeu de Normalização estabeleceu diversos métodos, sendo que a EN $1040^{17}$ é preliminar e as demais são específicas para lavagem higiênica e escovação cirúrgica das mãos, desde preliminares até práticos, aplicáveis em sua maioria a produtos para serem utilizados diluídos ${ }^{18}$.

A atividade in vitro de um agente antimicrobiano perante um determinado micro-organismo pode ser medida quantitativamente por métodos de diluição em meio de cultura líquido ou sólido. O resultado final é influenciado de maneira significativa pela metodologia, que deve ser cuidadosamente controlada para se obterem resultados reprodutíveis (intra e interlaboratório). Assim sendo, como no Brasil são comercializados diferentes tipos de antissépticos, é importante avaliar a qualidade dos produtos por meio de testes laboratoriais.

Uma das técnicas disponíveis é conhecida como Time Kill (Tempo de Morte). Nesta, uma diluição do produto-teste é colocada em contato com uma população conhecida de micro-organismos por um tempo de exposição específico a uma determinada temperatura. A atividade do produto de ensaio é inibida em intervalos na amostragem especificada com uma técnica de neutralização (diluição, agentes químicos ou outras) adequada e os micro-organismos sobreviventes contados.

O Guia Standard de Avaliação da Atividade Antimicrobiana cita este ensaio. Trata-se do
Procedimento de Estudo Teste ASTM E2315 Time Kill, no qual é avaliada a evolução de uma população de microorganismos aeróbios num período de tempo específico, quando testado frente a agentes antimicrobianos. Outros autores também descrevem técnicas semelhantes ao Time Kill como Hobson e Bolsen ${ }^{19}$ que se baseiam em recomendações do FDA. A principal finalidade desse teste é avaliar a redução da população microbiana de ensaio depois de ter sido exposto a produtos de teste ${ }^{19}$.

Além da caracterização da amplitude do espectro de micro-organismos contra os quais o antimicrobiano é eficaz, o teste do tempo de morte também deve ser um dos critérios utilizados para caracterizar os produtos. $\mathrm{O}$ produto antisséptico é testado sobre o tempo e o número de micro-organismos sobreviventes determinados pela contagem direta. A curva de morte gerada deve mostrar a redução microbiana no intervalo de tempo do uso previsto do produto antimicrobiano ${ }^{7,19}$.

Outros métodos utilizados pela comunidade europeia são baseados na capacidade dos produtos para reduzir a população microbiana. Por esses protocolos, os produtos devem atender à eficácia padrão: redução de 99,999\% na contagem de organismos no tempo estipulado pela técnica ou no tempo de contato recomendado pelo fabricante ${ }^{20}$.

O objetivo desse estudo é avaliar a atividade antimicrobiana, pelo estudo in vitro de produtos antissépticos à base de iodopolividona, digluconato de clorhexidrina, cloreto de benzalcônico, triclosano, determinando para uma dada concentração de cada material-teste o tempo de exposição necessário para eliminar completamente o crescimento dos organismos específicos incluídos no teste. O teste seguiu a norma ASTM E 2315 tempo de morte descrito por Hobson e Bolsen $^{19}$.

\section{MATERIAL E MÉTODOS}

Foram analisadas vinte e cinco amostras comerciais das preparações à base de PVP-I sol. degermante (iodopolividona $1 \%$ ), digluconato de clorhexidrina $0,2 \%, 1 \%$ e $4 \%$, nordexidina $0,5 \%$ e $1 \%$, cloreto de benzalcônico $1 \%$, triclosano $0,2 \%, 0,5 \%$ e $1 \%$. A solução de etanol a $70 \%$ serviu como controle positivo e a solução de etanol a $35 \%$ como controle negativo.

Foram utilizados os seguintes micro-organismos de referência cedidos pela Coleção de Micro-organismos de Referência em Vigilância Sanitária (CMRVS) do 
INCQS/FIOCRUZ: Pseudomonas aeruginosa INCQS 00025 (ATCC 15442), Staphylococcus aureus INCQS 00039 (ATCC 6538), Escherichia coli INCQS 00032 (ATCC 11229), Candida albicans INCQS 40006 (ATCC 10231). Foram incluídas também cepas de origem clínica, cedidas pela CMRVS de $S$. aureus e de $P$. aeruginosa isoladas de portador são e material clínico incluindo processos infecciosos em membros inferiores, urina e hemocultura.

Os inóculos foram preparados a partir de culturas de 24 horas em caldo caseína soja. Foram preparadas suspensões em solução de cloreto de sódio a $0,85 \%$ estéril, diluindo até se obter turbidez equivalente a $0,5-\mathrm{McF}$ arland ou $10^{8} \mathrm{UFC} / \mathrm{mL}$. Preparação das soluções de ensaio: os produtos antissépticos foram diluídos a 1:10 e também foram testados sem diluição. Foi utilizada a técnica baseada na descrição de Hobson e Bolsen ${ }^{19}$.

A $99 \mathrm{~mL}$ da solução-teste $1: 10$ (1 mL da amostra + $9 \mathrm{~mL}$ do diluente) e também do produto sem diluição foi adicionado $1 \mathrm{~mL}$ da suspensão-teste (micro-organismo a aproximadamente $\left.10^{8} \mathrm{UFC} / \mathrm{mL}\right)$. Imediatamente em cada tempo designado $(0,3,6,9,12,15,20$ e 30 minutos), foram retirados $3 \mathrm{~mL}$ da mistura (solução teste do antisséptico + suspensão do micro-organismo) e inoculados na porção de $1 \mathrm{~mL}$ em tubos contendo caldo Mueller Hinton, em triplicata. Alíquotas de $1 \mathrm{~mL}$ foram retiradas dos tubos com caldo Mueller Hinton, sendo uma alíquota semeada em Agar Mueller Hinton fundido e conservado à temperatura de aproximadamente $50^{\circ} \mathrm{C}$, semeado em profundidade e as outras duas alíquotas foram submetidas à filtração por membrana em filtro de acetato de celulose com porosidade de $0,45 \mu \mathrm{m}$. A seguir, as membranas foram colocadas sobre a superfície de Agar Mueller Hinton em placa. Foi realizado o mesmo procedimento para todos tempos de contato. As placas e os tubos foram incubados à temperatura de $35 \pm 2{ }^{\circ} \mathrm{C}$ por $24 / 48$ horas. Após o período de incubação, foi verificado o crescimento microbiano.

Controles: Foi adicionado $1 \mathrm{~mL}$ dos micro-organismos teste da suspensão 0,5-McFarland (aproximadamente $10^{8} \mathrm{UFC} / \mathrm{mL}$ ) diluído até $10^{-8}$ em cinco tubos contendo a solução teste e caldo Mueller Hinton modificado (com $1 \mathrm{~mL}$ de polisorbato 80 e $1 \mathrm{~mL}$ de lecitina de soja); imediatamente foi plaqueado metade do volume dos tubos no tempo zero $\left(\mathrm{T}_{0}\right)$ em duplicata e metade após 30 minutos $\left(\mathrm{T}_{30}\right)$ em duplicata. Em seguida foram incubados, e registrados o número de $\mathrm{UFC} / \mathrm{mL}$.
Critérios de aceitação: Os produtos foram considerados antissépticos satisfatórios quando não ocorreu crescimento microbiano nos tempos de 3, 6, $9,12,15,20$ e 30 minutos e os controles mostraram crescimento tanto na presença quanto na ausência da amostra.

\section{RESULTADOS E DISCUSSÃO}

Foram analisadas 35 amostras à base de: álcool etílico $70 \%$ (A70\%1, A70\%2, A70\%3, A70\%4, A70\%5); álcool etílico $35 \%$ (B35\%1, B35\%2, B35\%3, B35\%4, B35\%5); PVP-I solução degermante $1 \%$ (C1\%1, C1\%2, $\mathrm{C} 1 \% 3, \mathrm{C} 1 \% 4, \mathrm{C} 1 \% 5)$; digluconato de clorexidrina (D0,2\%1, D0,2\%2, D1\%3, D1\%4, D4\%5); nordexidina (E0,5\%1, E0,5\%2, E1\%3, E1\%4, E1\%5); cloreto de benzalcônico (F1\%1, F1\%2, F1\%3, F1\%4, F1\%5) e triclosano (G0,2\%1, G0,5\%2, G1\%3, G1\%4, G1\%5). A Tabela 1 apresenta os resultados da avaliação da atividade antimicrobiana dos antissépticos estudados, para as cepas de referência e as cepas clínicas.

Observa-se que as amostras à base de etanol a $35 \%$ e de digluconato de clorexidina foram insatisfatórias para todas as cepas de micro-organismos de referência, porém apresentaram-se satisfatórias diante das cepas de origem clínica. Assim, das 25 amostras de produtos comerciais estudadas, $20 \%$ foram insatisfatórias (Tabela 1).

Os resultados obtidos mostraram que os produtos possuem atividade antimicrobiana frente aos patógenos testados, com exceção das amostras à base de digluconato de clorexidina, que em todas as fases do teste apresentou crescimento microbiano, quando avaliadas em comparação às cepas de referência.

Os produtos à base de clorexidina e a solução de etanol a $35 \%$, como foram insatisfatórios, proporcionaram uma avaliação da técnica de recuperação dos microorganismos sobreviventes por meio de semeadura em profundidade e por filtração em membrana. A Figura 1 mostra os resultados dos ensaios realizados com as cepas de $P$. aeruginosa. Podemos observar que o método de semeadura em profundidade permitiu a recuperação de um número maior de micro-organismos.

Devido à importância das IRAS e da necessidade de medidas preventivas eficazes, a Portaria 2616/1998 ${ }^{21}$ estabelece as diretrizes e normas para prevenção e controle das infecções hospitalares, incluindo, em seu Anexo V, uma relação de princípios ativos não recomendados para a finalidade de antissepsia, mas 
Nóbrega HN, Ferreira JAB, Romão CMCPA, Capasso IRVF. Atividade antimicrobiana in vitro de produtos antissépticos por meio de técnica time kill. Rev Inst Adolfo Lutz. São Paulo, 2013; 72(3):226-33.

Tabela 1. Atividade antimicrobiana de produtos antissépticos frente a cepas de referência e cepas clínicas por técnica de Time Kill

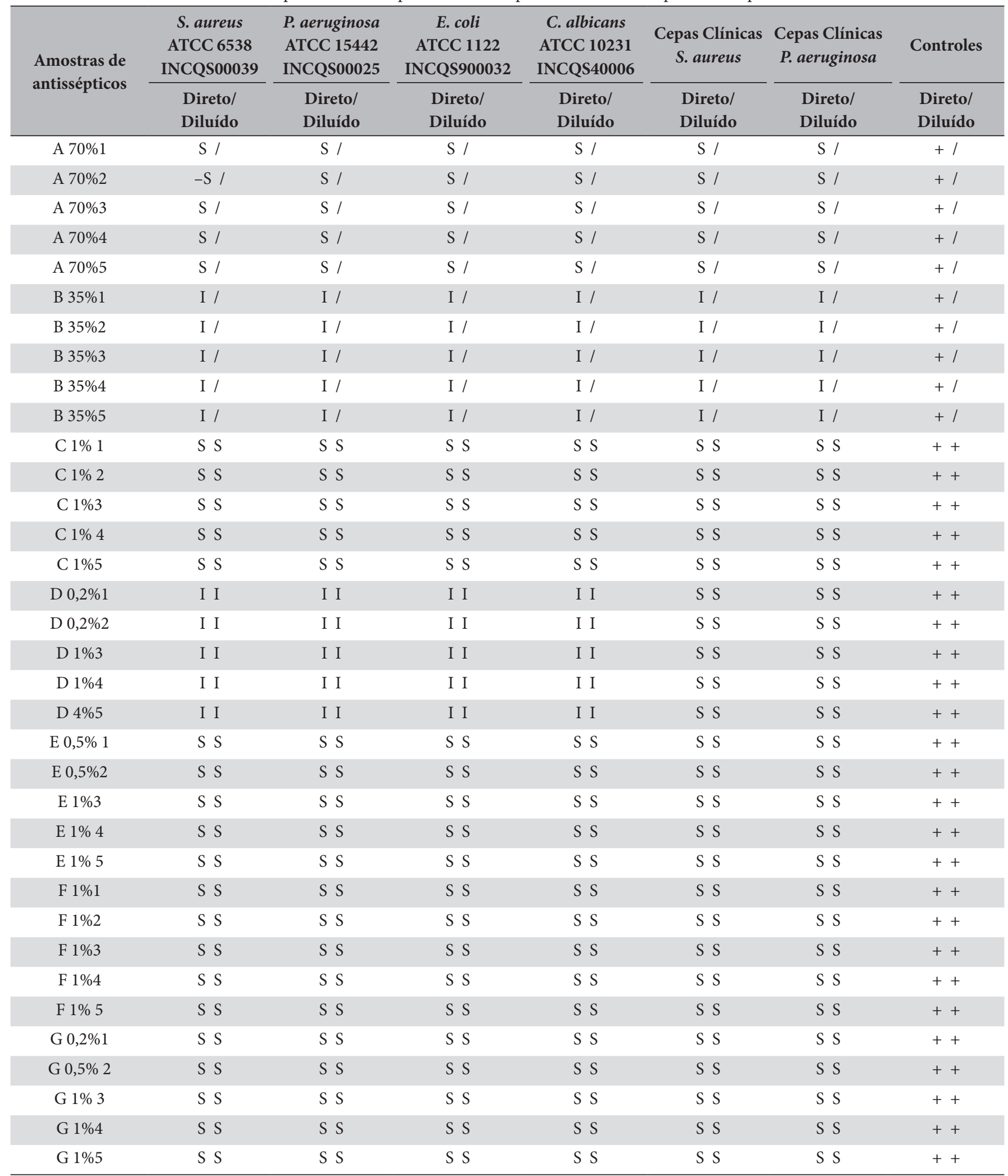

S: Satisfatório; I: Insatisfatório; + Presença de crescimento; /:Não realizado; A: álcool etílico 70 \%;

B: álcool etílico 35 \%; C: PVP-I solução degermante; D: digluconato de clorhexidrina; E: nordexidina; F: cloreto de benzalcônico; G: triclosano1 \% 
não há menção aos recomendados para uso em seres humanos. Em tal legislação também é possível constatar o fato da inexistência de uma regulamentação específica com uma metodologia para o controle da eficácia de antissépticos em geral.

A clorexidina foi aprovada para o uso em escovas cirúrgicas em meados dos anos 1970, e como colutório a $0,12 \%$, no final da década 1980 . No entanto, hoje já se encontram produtos mais eficientes. Não há relatos da eficácia deste produto como solução tópica até o momento. Apesar da clorexidina possuir ampla atividade antimicrobiana, a inativação dos micro-organismos ocorre muito mais lentamente quando comparada com o álcool, não sendo considerada eficiente para inativar micro-organismos Gram-negativos, mas apresentando uma maior eficácia contra bactérias Gram-positivas ${ }^{13}$.

O álcool também está entre os antissépticos mais seguros, não só por possuir baixa toxicidade, mas também pelo seu efeito microbicida rápido e por ser de fácil aplicação. Desta forma, provê rápida antissepsia em procedimentos como punções venosas e é excepcional para higienização das mãos².

A contaminação de soluções antissépticas não está sendo, até o momento, associada à redução de susceptibilidade dos micro-organismos. Portanto, qualquer que seja a molécula utilizada, os valores de sua Concentração Inibitória Mínima (CIM) devem ser conhecidos para permitir que a dosagem correta seja inferida para as necessidades de seu uso, e para que seja diluída ou inativada adequadamente antes de seu descarte ${ }^{22}$.

Para que haja o emprego correto dos antissépticos, do ponto de vista de custo e qualidade, é necessário que os produtos adquiridos tenham registro na Anvisa, venham acompanhados de certificado de análise do fabricante e que, na utilização, o estabelecimento disponha de um responsável farmacêutico para sua avaliação, aquisição e manipulação ${ }^{2}$.

Atualmente a literatura existente sobre agentes químicos antimicrobianos utilizados em antissepsia ainda se apresenta confusa e contraditória, principalmente pela falta de padronização dos métodos de ensaio e, consequentemente, pela diversidade de condições experimentais ${ }^{13}$.

Considerando a missão do INCQS, que é a de contribuir para a promoção e recuperação da saúde e prevenção de doenças, atuando como referência nacional para as questões científicas e tecnológicas relativas ao controle da qualidade de produtos, ambientes e serviços vinculados à vigilância sanitária, é importante, como já ressaltado, o estabelecimento de métodos que possam avaliar a qualidade dos produtos de interesse para a saúde, incluindo os antissépticos.

Pelos resultados obtidos foi possível verificar que, das 25 amostras comerciais avaliadas, apenas aquelas à base de clorexidina apresentaram insatisfatoriedade para o teste, ou seja, não foram capazes de destruir os microorganismos de referência em nenhuma das concentrações e em nenhum dos tempos de contato determinados pelo procedimento.

Adicionalmente, foi avaliado o procedimento de recuperação dos micro-organismos sobreviventes, no caso das amostras insatisfatórias. Assim, foram utilizadas as técnicas de semeadura em profundidade e filtração por membrana. Com base nos dados obtidos, observamos que a técnica por filtração por membrana mostrou-se menos sensível, uma vez que o número de colônias foi menor do que o obtido pela semeadura em profundidade, esta bem mais sensível, possibilitando a detecção de um maior número de colônias.

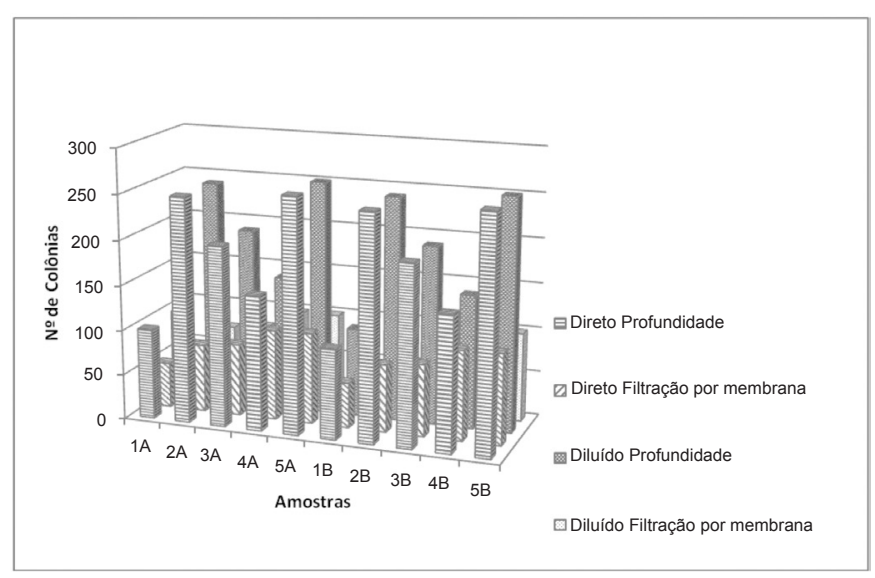

Figura 1. Comparação entre as amostras não diluídas e não diluídas de dicluconato de clorexidina e álcool etílico a $35 \%$, que apresentaram presença de $P$. aeruginosa, por semeadura em profundidade e filtração por membrana

Os antissépticos à base de digluconato de clorexidina não foram capazes de inibir o crescimento da $P$. aeruginosa ATCC 15442, INCQS 00025 e também dos outros micro-organismos (com exceção daqueles de origem clínica, que não apresentaram contagem). Esse dado é preocupante por se tratar de produto utilizado em ambiente hospitalar e pelo fato de $P$. aeruginosa ser um dos patógenos mais frequentes em 
processos infecciosos de ambiente hospitalar ${ }^{5,22}$. Os demais produtos antissépticos apresentaram atividade antimicrobiana nos tempos de contato empregados frente às cepas de referência e às cepas clínicas.

Alguns trabalhos descrevem a contaminação do digluconato de clorexidina, como fonte comprovada de surtos hospitalares. Ressalta-se a atividade dos produtos antissépticos, inclusive em sua menor concentração $0,1 \%$, como foi também observado por Reis et $\mathrm{al}^{22}$, que analisaram antissépticos à base de álcool etílico a $70 \% \mathrm{e}$ PVPI e obtiveram resultados semelhantes aos das amostras analisadas no presente estudo, utilizando as cepas de referência.

Estudando a atividade de antissépticos por um outro método Time Kill, testado apenas em relação à cepa de Candida albicans, Atayese et $\mathrm{a}^{23}$ mostraram que tais produtos foram menos efetivos diante deste microorganismo.

Entre todas as amostras de antissépticos testadas no presente estudo, apenas aquelas à base de clorexidina foram insatisfatórias quanto à inativação de microorganismos considerados patológicos. Apesar de se tratar de um número baixo de amostras insatisfatórias, essa falha poderia ter graves consequências em um hospital, onde a assepsia é fator primordial para garantir a segurança de seus procedimentos de rotina. Entretanto, foi observado que as cepas clínicas mostraram-se susceptíveis aos produtos.

De um modo geral, um agente antimicrobiano deve apresentar as condições ideais para que tenha um amplo espectro de ação: ser estável em solução; ser compatível química e biologicamente com outros ingredientes da formulação; ser bem tolerado pelo tecido humano; não apresentar toxicidade em caso de um emprego prolongado. Na realidade, de acordo com Foster $^{24}$, nenhum dos antissépticos usuais reúne todas estas características, fato que deve ser cuidadosamente avaliado juntamente com as características antimicrobianas destes produtos ${ }^{24}$.

Devido à sua alta resistência aos antimicrobianos, às bactérias do gênero Pseudomonas, que também são comuns no ambiente e muito resistentes a diversos produtos químicos, podendo até mesmo crescer em alguns antissépticos ${ }^{25}$, ou não serem susceptíveis, como foi o caso do digluconato de clorexidina, o que foi comprovado neste trabalho.

Por se tratar de produtos que fazem parte de programas de controle e prevenção de infecções nos estabelecimentos de saúde consideramos que o presente estudo é inédito, pois todas as publicações relacionadas discutem apenas a possível relação da contaminação com surtos em estabelecimentos de saúde; não há nesses estudos nenhuma informação sobre a atividade antisséptica medida por testes como o Time Kill descrito por Hobson e Bolsen ${ }^{19}$.

As análises realizadas nos permitem inferir que o teste Time Kill descrito por Hobson e Bolsen ${ }^{19}$ foi adequado para o estudo da atividade antimicrobiana in vitro de produtos antissépticos. Os resultados deste estudo trazem respostas para a prática do uso de antissépticos, que até o momento tem se mostrado apenas parcialmente eficaz do ponto de vista científico. Além disso, o presente trabalho aponta para a gravidade da inexistência de uma legislação específica. Podemos, portanto, afirmar que a utilização dos produtos estudados no processo de antissepsia é prática e segura, agregando facilidades e economia nas instituições de saúde.

\section{CONCLUSÃO}

Os produtos à base de álcool etílico, PVP-I solução degermante iodopolividona, nordexidina, cloreto de benzalcônico e triclosano, mostraram resultado satisfatório frente às cepas clínicas e de referência.

$\mathrm{O}$ digluconato de clorexidrina, apesar de ser menos tóxico, não mostrou atividade diante da $P$. aeruginosa e dos outros micro-organismos de referência. Concluímos, portanto, que esse produto deve ser utilizado com cautela e estudos adicionais são necessários, apesar de ter apresentado eficácia contra cepas clínicas.

A técnica de semeadura em profundidade mostrou-se mais sensível do que a de filtração em membrana para recuperação de micro-organismos sobreviventes após o contato com os antissépticos.

Nosso estudo poderá auxiliar as ações de vigilância sanitária e saúde pública na elaboração de futuras legislações, uma vez que esses produtos são encontrados no comércio, mas não estão submetidos a nenhuma legislação específica e não existem dados suficientes, até o momento, que atestem sua real eficácia.

\section{REFERÊNCIAS}

1. Moriya T, Módena JLP. Assepsia e antissepsia: técnicas de esterilização. Medicina (Ribeirão Preto). 2008;41(3):265-73.

2. Santos AAM, Verotti MP, Sanmartin JA. Importância do álcool no controle de infecções em serviço de saúde. RAS. 2002;4(16): 7-14.

3. Hanberger H, Garcia-Rodriguez JA, Gobernado M, Goossens H, Nilsson LE, Struelens MJ. Antibiotic Susceptibility among 
Nóbrega HN, Ferreira JAB, Romão CMCPA, Capasso IRVF. Atividade antimicrobiana in vitro de produtos antissépticos por meio de técnica time kill. Rev Inst Adolfo Lutz. São Paulo, 2013; 72(3):226-33.

Aerobic Gram-negative Bacilli in intensive Care Units in 5 European Countries. J Amer Med Assoc.1999;281(1):67-71.

4. Pellegrino FL, Teixeira LM, Carvalho MMG. Occurrence of a multidrug-resistant Pseudomonas aeruginosa clone in different hospitals in Rio de Janeiro, Brazil. J Clin Microbiol. 2002; 40(7): 2420-4.

5. Pires, EJVC. Análise epidemiológica de isolados clínicos de Pseudomonas aeruginosa provenientes de hospital universitário. Rev Bras Ter Intens. 2009;21(4):384-90.

6. Brasil. Lei $\mathrm{n}^{\circ} 8.080$, de 19 de Setembro de 1990. Dispõe sobre as condições para a promoção, proteção e recuperação da saúde, a organização e o funcionamento dos serviços correspondentes, e dá outras providências. Diário Oficial [da] República federativa do Brasil. Brasília, DF, 20 set 1990. Disponível em: http://portal. saude.gov.br/portal/arquivos/pdf/lei8080.pdf

7. Crabtree BF, Miller WL. Using Codes and Code Manuals: a Template Organizing Style of Interpretation. In: Doing qualitative research in primary care: multiple strategies. 2. ed. Newbury Park, CA: Sage Publications; 1999. p.163-177.

8. Koneman EW, Allen SD, Janda WM. Diagnóstico Microbiológico: texto e atlas colorido. 6 ed., Rio de Janeiro: Medsi, 2001. p.87-90

9. Weber DJ, Rutala WA. Use of germicides in the home and the healthcare setting: is there a relationship between germicide and antibiotic resistence? Infect Control Hosp Epidemiol. 2006; 27(10): 1107-19.

10. Teixeira P, Valle S. Biossegurança: uma abordagem multidisciplinar. Rio de Janeiro: Ed. Fiocruz, 1996.

11. Food And Drug Administration - FDA. Tentative final monograph for health-care antiseptic drug products: proposed rule. Federal Register, 1994. p.31402-31452.

12. Souza ELC. Comparação do dogluconato de clorexidina $0,12 \%$ com e sem xylitol para controle do biofilme oral e efeitos adversos associados. [dissertação de mestrado]. Rio de Janeiro, RJ: Universidade Veiga de Almeida; 2007.

13. Murray PR, Rosenthal KS, Kobayashi GS, Pfaller MA. Manual of clinical microbiology. 9. ed. Washington D.C.: American Society of Microbiology, 2007. p.1183-1185.

14. Brasil. Ministério da Saúde. Resolução RDCn ${ }^{\circ} 42$, de 25 de outubro de 2010. Dispõe sobre a obrigatoriedade de disponibilização de preparação alcoólica para fricção antisséptica das mãos, pelos serviços de saúde do País, e dá outras providências. Diário Oficial [da] República federativa do Brasil. Brasília, DF, 26 out 2010. Disponível em: http://bvsms.saude.gov.br/bvs/saudelegis/ anvisa/2010/res0042_25_10_2010.html

15. Tortora GJ, Funke BR., Case CL. Microbiologia. 7 ed. Porto Alegre: Artmed, 2002.

16. Roessler WG. Methods of Testing Antiseptics. In: Block SS. Desinfecção, Esterilização e Preservação. 3 ed. Philadelphya: Lea \& Febiger, 1983. p.100-106.

17. European Standard, EN1040: Chemical disinfectants and antiseptics - Quantitative suspension test for the evaluation of basic bactericidal activity of chemical disinfectants - Test method and requirements, 2005.

18. Austrian Standards Institute. EN 14885: Chemical disinfectants and antiseptics: application of European Standards for chemical disinfectants and antiseptics. Wien; 2007.

19. Hobson DW, Bolsen K. Methods of testing oral and topical antiseptics and antimicrobials. In: Block SS. Disinfection, Sterilization, and Preservation. 5. ed. Philadelphia, Pa: Lippincatt Williams and Wilkins; 2001. p.1329-1358.

20. AFNOR. Normes \& Réglementation: Antiseptiques et Disinfectants. Paris: AFNOR, 1998.

21. Brasil. Portaria no 2616, de 12 de maio de 1998. Controle de infecção hospitalar. Diário Oficial [da] República Federativa do Brasil. Brasília, DF 13 mai 1998. Disponível em: [http://portal. anvisa.gov.br/wps/wcm/connect/8c6cac8047457a6886d6d63fbc 4c6735/PORTARIA+N\%C2\%B0+2.616,+DE+12+DE+MAIO+ $\mathrm{DE}+1998 . p d f ? \mathrm{MOD}=\mathrm{AJPERES}]$.

22. Reis LM, Rabello BR., Ross C, Santos LMR. Avaliação da atividade antimicrobiana de antissépticos e desinfetantes utilizados em serviço de saúde. Rev Bras Enferm. 2011; 64(5): 870-5.

23. Atayese AO, Effedua HI, Oritogun KI, Kareem KT, Oluwadun A. Comparative study of the antimicrobial activity of chlorinated and non-chlorinated antiseptics against C. albicans. Acad Arena. 2010;2(9):35-40.

24. Foster JSH. Preservation of ophythalmic solutions. Manufact Chem Aerosol News. 1965;2:43-6.

25. Balows A, Hausler, William J. Manual of clinical microbiology. 5.ed. Washington, D.C: American Society of Microbiology, 1991. 